\title{
Glycated Hemoglobin in the Pre and Diabetes Ranges as Related to Lipid Cardiovascular Risk
}

\author{
Bernardo M Machado de Almeida ${ }^{1}$, Carolina Queiroz Cardoso ${ }^{1}$, Anita L R Saldanha ${ }^{1}$, Marileia Scartezini $^{1}$, Caio Corsi Klosovski ${ }^{1}$, Ana \\ Paula Pantoja Margeotto ${ }^{1}$, Andre L V Gasparoto ${ }^{2}$, Abel Pereira ${ }^{1}$, Tereza Luiza Bellincanta1, Tania Leme da Rocha Martinez ${ }^{1 *}$ \\ ${ }^{1}$ Nephrology Department, BP - A Beneficência Portuguesa de São Paulo, São Paulo, Brazil. \\ ${ }^{2}$ Intensive Care Unit, BP - A Beneficência Portuguesa de São Paulo, São Paulo, Brazil.
}

*Corresponding Author: Tania Leme da Rocha Martinez, BP - A Beneficência Portuguesa de São Paulo Rua Comandante Ismael Guilherme, SP, Brazil.

\section{Received Date: 26 July 2021 | Accepted Date: Augusł 132021 | Published Date: August 172021}

Citation: B M M Almeida, Carolina Q Cardoso, A L R Saldanha, M Scartezini, T L R Martinez, et al. (2021) Glycated Hemoglobin in the Pre and Diabetes Ranges as Related to Lipid Cardiovascular Risk. Cardiology Research and Reports. 3(3): DOI:10.31579/2692-9759/028

Copyright: ( 2021 Tania Leme da Rocha Martinez, This is an open-access article distributed under the terms of the Creative Commons Attribution License, which permits unrestricted use, distribution, and reproduction in any medium, provided the original author and source are credited.

\begin{abstract}
The concomitance of diabetes metabolic markers, as Glycated Hemoglobin and blood glucose, together with lipid changes; Cholesterol and fractions and Triglycerides, occurs very frequently but not always in the same pairs of markers, being its peculiarities important factors for the estimation of the cardiovascular risk. Not only has the association of high glucose levels and high triglycerides pointed to an augmented risk. The study of the correlations of the parameter Glycated Hemoglobin with all the values of the lipid profile may help gain a broader insight as to the associated risks. A database of 548 individuals with concomitant results of HbAlC, triglycerides, CT and HDL-c were applied statistical tests of ANOVA and Tukey. Most of the 546 individuals tested for glycated hemoglobin (HbA1C) and lipid profile had HbA1C levels within normal range (49.8\%), $15.4 \%$ were classified as prediabetic, and $34.8 \%$ had HbA1C levels above $6.4 \%$ (diabetics). The overall mean HbA1C observed was $6.3 \%$, and triglycerides was $236.8 \mathrm{mg} / \mathrm{dL}$. Data from HbA1C-lipid profile comparations are not superimposed, as expected, to the combinations of fasting glucose and triglycerides. In not accompanying lipids concomitantly with $\mathrm{HbA} 1 \mathrm{C}$, the correct assessment of the overall risk calculation for atherosclerosis can be omitted. In conclusion, HbA1C levels should be added to the lipid profile for a more accurate estimation of the cardiovascular risk.
\end{abstract}

Keywords: glycated hemoglobin, blood glucose; cholesterol; triglycerides; hdl cholesterol

\section{Introduction}

There is a very frequent simultaneity of changes in blood glucose and triglycerides, however the same does not occur for Glycated Hemoglobin (HbA1C). The atherosclerotic disease prevention recommendations is that all multifactorial risk markers must be taken into consideration [1-6].

\section{Objective}

To evaluate the comparison of $\mathrm{HbA} 1 \mathrm{C}$ data with those of total cholesterol (TC), triglycerides and HDL cholesterol (HDL-c) collected simultaneously in a cohort large enough to point out the existence or not of significance.

\section{Method}

A database of 548 individuals with concomitant results of HbA1C, triglycerides, CT and HDL-c were applied statistical tests of ANOVA and
Tukey.

HbA1C: The HbA1C total blood measurement method, in the Hilab remote laboratory test (RLT), is a quantitative immunoassay based on the principle of sandwich binding with two antibodies. Cholesterol: colorimetric enzymatic method (RLT). HDL-c: by precipitation.

Triglycerides: Triglycerides are evaluated in reactive strip by colorimetric enzymatic reaction. The Hilab RLT uses reflectance photometry and the results can be evaluated between 120 and $400 \mathrm{mg} / \mathrm{dL}$.

\section{Results}

Most of the 546 individuals tested for glycated hemoglobin (HbA1C) and lipid profile had $\mathrm{HbA} 1 \mathrm{C}$ levels within normal range $(49.8 \%), 15.4 \%$ were classified as prediabetic, and $34.8 \%$ had HbA1C levels above $6.4 \%$ (diabetics). The overall mean HbA1C observed was $6.3 \%$, and triglycerides was $236.8 \mathrm{mg} / \mathrm{dL}$ (Table 1). 


\begin{tabular}{|c|c|c|c|c|c|}
\hline Analyt & Minimum & Average & Maximum & $\mathbf{1 Q}$ & 3Q \\
\hline Glycated Hemoglobin (\%) & 2.7 & 6.3 & 14.5 & 4.87 & 7.08 \\
\hline Triglycerides (mg/dL) & 120.1 & 236.8 & 399.8 & 168.87 & 299.43 \\
\hline Total Cholesterol (mg/dL) & 120.2 & 202.1 & 374.7 & 159.93 & 236.82 \\
\hline HDL-c (mg/dL) & 20.6 & 49.6 & 99.1 & 38.71 & 57.81 \\
\hline
\end{tabular}

Table 1: Descriptive summary of glycated hemoglobin and lipid profile analydes.

We found a significant difference in the mean triglycerides between those with levels below 5.7\% and the other two categories (F2=17.04, $\mathrm{p}<0.0001$; Tukey's post-hoc: $<5.7 \%$ vs $5.7-6.4 \% \mathrm{p}=<0.0222 ;<5.7 \%$ vs $>6.4 \% \mathrm{p}<0.0001)$. The mean total cholesterol also varied significantly between the clinical ranges of $\mathrm{HbA} 1 \mathrm{C}(\mathrm{F} 2=7.04, \mathrm{p}=0.0010)($ Table 2$)$.

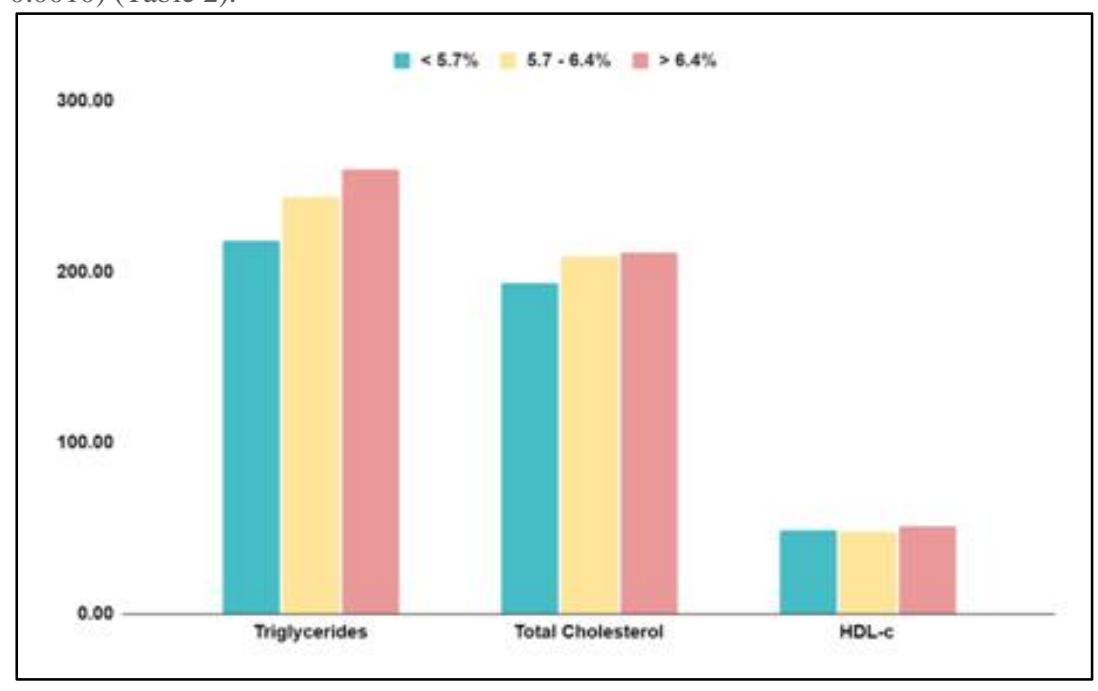

Figure 1: Graphical representation of lipid profile according to HbAlC ranges.

\begin{tabular}{|c|c|c|c|c|c|c|c|}
\hline & \multicolumn{7}{|c|}{ Glycated Hemoglobin (HbA1C) } \\
\hline & \multicolumn{2}{|c|}{$<5,7 \%$} & \multicolumn{2}{|c|}{$5,7-6,4 \%$} & \multicolumn{2}{|c|}{$>6,4 \%$} & \\
\hline & \multicolumn{2}{|c|}{$\mathrm{n}=272(49,8 \%)$} & \multicolumn{2}{|c|}{$\mathrm{n}=84(15,4 \%)$} & \multicolumn{2}{|c|}{$\mathrm{n}=190(34,8 \%)$} & ANOVA \\
\hline & Average & SD & Average & SD & Average & SD & p \\
\hline Triglycerides & 218.22 & 76.11 & 243.84 & 74.82 & 260.36 & 79.96 & $<0.0001$ \\
\hline Total Cholesterol & 193.32 & 51.59 & 209.33 & 57.95 & 211.46 & 57.29 & 0.0010 \\
\hline HDL-c & 48.82 & 14.33 & 48.08 & 15.48 & 51.29 & 16.19 & 0.1430 \\
\hline
\end{tabular}

Table 2: Means and standard deviation (SD) of lipid profile analytes by clinical range of Glycated hemoglobin and p-value of the ANOVA test comparing analyte means between clinical ranges.

\section{Discussion}

Data from HbA1C-lipid profile comparations are not superimposed, as expected, to the combinations of fasting glucose and triglycerides. In not accompanying lipids concomitantly with $\mathrm{HbA1C}$, the correct assessment of the overall risk calculation for atherosclerosis can be omitted.

\section{Conclusion}

Whenever possible, HbA1C assay should be should be interpreted together with the lipid profile for a more comprehensive assessment of the overall risk of the patient for atherosclerosis.

\section{Acknowledgments}

To Mr. Marcus Vinícius Mazega Figueredo, $\mathrm{PhD}$ in Information
Technology, CEO at Hi Technologies SA, for providing the means for better understanding of the data obtained at the hospital regarding patients that were referred from all over the country.

\section{Conflicts of interest}

None.

\section{References}

1. Geva M, Shlomai G, Berkovich A, et al. (2019). The association between fasting plasma glucose and glycated hemoglobin in the prediabetes range and future development of hypertension. Cardiovasc Diabetol. 18(1): 53. 
2. Chen CL, Yen DH, Lin CS, et al. (2017). Glycated hemoglobin level is an independent predictor of major adverse cardiac events after nonfatal acute myocardial infarction in nondiabetic patients: A retrospective observational study. Medicine (Baltimore). 96(18): 6743.

3. Shin D, Ahn J, Cha KS, et al. (2016). Impact of initial glycosylated hemoglobin level on cardiovascular outcomes in prediabetic patients with ST-segment elevation myocardial infarction undergoing primary percutaneous coronary intervention. Coron Artery Dis. 27(1): 40-46.
4. D'Aurea CVR, Cerazi BGA, Laurinavicius AG, et al. (2017). Association of subclinical inflammation, glycated hemoglobin and risk for obstructive sleep apnea syndrome. Einstein (Sao Paulo). 15(2): 136-140.

5. Ewid M, Sherif H, Billah SMB, et al. (2019). Glycated hemoglobin predicts coronary artery disease in non-diabetic adults. BMC Cardiovasc Disord. 19(1): 309.

6. Xie J, Hu S. (2018). Apolipoprotein B is not superior to nonhigh-density lipoprotein cholesterol for dyslipidemic classification of glycated hemoglobin-defined diabetic patients. Medicine (Baltimore). 97(42): 12896.

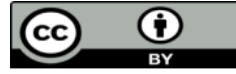

This work is licensed under Creative Commons Attribution 4.0 License

To Submit Your Article Click Here: Submit Manuscript

DOI: $10.31579 / 2692-9759 / 028$
Ready to submit your research? Choose Auctores and benefit from:

* fast, convenient online submission

* rigorous peer review by experienced research in your field

* rapid publication on acceptance

* authors retain copyrights

* unique DOI for all articles

* immediate, unrestricted online access

At Auctores, research is always in progress.

Learn more www.auctoresonline.org/journals/cardiology-research-andreports 